\title{
critical indigenous theory
}

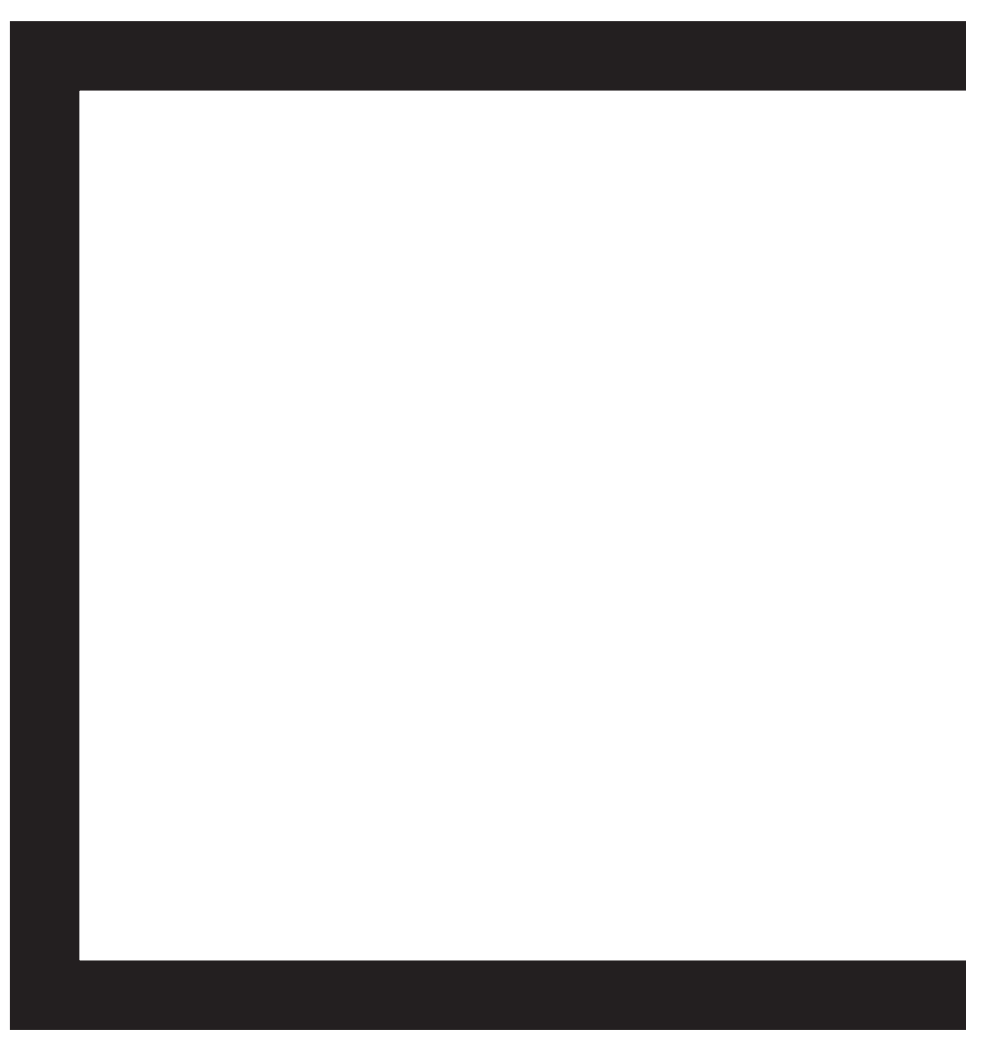




\section{introduction \\ Critical Indigenous Theory \\ AILEEN MORETON-ROBINSON}

This special edition of Cultural Studies Review grew out of the Indigenous Studies Research Network, which is located at the Queensland University of Technology in Brisbane, Australia. All the contributors are members of the network and this edition showcases critical theory developed from our respective standpoints and epistemologies. As scholars we are politically and intellectually engaged in demonstrating how critical Indigenous studies as a mode of analysis can offer accounts of the contemporary world of Indigenous peoples that centre our ways of knowing and theorising. Our writing is challenging and innovative, engaging theory to philosophise and apply to questions that concern us and our communities. These new conceptual models have grown productively out of the object of our study: the postcolonising world we inhabit. Our respective geographical locations are framed by nation states such as the USA, Canada, Australia and New Zealand where colonisation has not ceased to exist; it has only changed in form from that which our ancestors encountered.

Colonisation morphologises in multiple ways as it continues to operate discursively and materially within cultural formations, institutions and public culture. The first article in this volume, by Jodi Byrd, demonstrates how the frontier narrative of manifest destiny operated discursively within different cultural formations in the 2008 USA presidential electoral process, through appeals to an inclusive politics based on the absence of Native Americans, while being framed by their dispossession. Bronwyn Fredericks examines how health environments reproduce whiteness in space and place. This reproduction impacts on the health of Indigenous women as it hinders their use of such environments because they consider them to be white domains; spaces that signify exclusion and the omnipresence of white possession. Irene Watson explicates how the originary violence of the state against 
Indigenous people continues in different forms as a means of maintaining its existence and the life of its subjects. The violence of the state, masquerading as protection, is enacted through various regulatory mechanisms such as the military, the police, the law and government bureaucracies. The colonial project continues in contemporary forms as evidenced by the Northern Territory intervention, the construction of Aboriginal identity, the Hindmarsh Island affair and native title. The focus of Aileen Moreton-Robinson's analysis is the Northern Territory intervention. Drawing on Foucault's work on sovereignty and rights she argues that patriarchal white sovereignty as a regime of power deploys a discourse of pathology as a means to discipline Indigenous people into becoming 'good citizens', through constructing a state of exception that enables its own pathological behaviour.

Chris Andersen turns his analysis to knowledge production. He argues that Native studies would benefit from teaching whiteness studies as part of the curriculum as a way of revealing whiteness and decentring its normalising effects, thus making it productive and enabling in our teaching and thinking about the deep complexity of Indigeneity. Brendan Hokowhitu provides a theoretical framework for Indigenous existentialism, arguing that concepts such as tradition and authenticity are a colonial legacy that circulates within Indigenous studies and inhibit the development of a conscious awareness of the cultural immediacy of the Indigenous body. What is required is an understanding of the body as materiality and thought, as a site where historical and physiological contexts interact to produce social meaning. Robert Warrior explores why transnationalism as a category of analysis, which has currency within cultural and literary studies, is under utilised within Native American scholarship. Warrior argues that while transnationalism has much to offer, its epistemological premises conflict with Native American scholarship, which is primarily concerned with developing its own theoretical agenda that centres the Indigenous world.

We hope this special edition, which is the last hard-copy version of Cultural Studies Review, stimulates interest and begins an overdue dialogue with those who teach and research within the discipline of cultural studies. 